\title{
9. Media skills for daily life: Designing a journalism programme for graduates of all disciplines
}

\section{ABSTIRACII}

This article in the journalism education field reports on the construction of a new subject as part of a postgraduate coursework degree. The subject, or unit ${ }^{1}$ will offer both Journalism students and other students an introductory experience of creating media, using common 'new media' tools, with exercises that will model the learning of communication principles through practice. It has been named 'Fundamental Media Skills for the Workplace'. The conceptualisation and teaching of it will be characteristic of the Journalism academic discipline that uses the 'inside perspective'understanding mass media by observing from within. Proposers for the unit within the Journalism discipline have sought to extend the common teaching approach, based on training to produce start-ready recruits for media jobs, backed by a study of contexts, e.g. journalistic ethics, or media audiences. In this proposal, students would then examine the process to elicit additional knowledge about their learning. The article draws on literature of journalism and its pedagogy, and on communication generally. It also documents a 'community of practice' exercise conducted among practitioners as teachers for the subject, developing exercises and models of media work. A preliminary conclusion from that exercise is that it has taken a step towards enhancing skills-based learning for media work.

Keywords: community of practice, curriculum development, ethics, journalism pedagogy, new media, skills-based learning

\section{LEE DUFFIELD}

Queensland University of Technology 


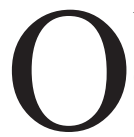

VER THREE months in late 2010 a new unit, or subject, for coursework studies in journalism and media was proposed, constructed in outline, and approved for offering from the end of 2011, at the Queensland University of Technology in Brisbane. This article is a pedagogical study in the curriculum building field, which explains the conceptualisation of the unit, and describes the implementation process.

It has two main claims to interest among media educators and others. The first is that the unit has been conceived as a refinement of the idea of teaching principles through practice. That idea, is that skills-based units, common in Journalism courses especially, will be run in parallel with 'theory' units dealing with journalistic issues, (typically ethics, law or regulatory environments for journalism); that these studies will help to inform what is being done in the skills-based units, and that students will be able to learn by drawing inferences about principles, e.g. principles of human communication, that underlie their practice. Detecting and observing this learning process defies analysis. Outcomes might be relied on as something of a guide to a depth of understanding being acquired, in that generations of graduates go on to work successfully in the mass media. In the present case, an effort is to be made to build into the experience of students, through simultaneously addressing production and issues or principles, a yet more conscious realisation of the nature of communication activity inherent in their practice. The effort will be extended to try and find evidence for how that learning process takes place-a transfer from doing to knowing, to be the cause of knowingly-doing.

The second claim to interest on the part of this new subject, is that it has been given a foundational principle, to consider all matters to do with doing media strictly from a practitioner perspective. The premise offered here is that having that express stance as a guideline may help students to think out more openly and explicitly the implications of their practice. Adam has articulated thought of this kind, regarding journalism as a form of expression that achieves 'distinctive forms of knowledge' (2001, pp. 331-35); saying that study for entry into journalism will involve 'thoughtful understanding of news judgment' (p. 317), and its graduates will emerge as 'reporters, writers-and critics' (p. 327). An additional element in the proposal was to introduce some methodological approaches found in general communication theory as a further aid to students in analysing the import of their practical work. This would refer to long-standing devices for framing acts of communication, at 
interpersonal, organisational or mass level; for instance an early process or transactional model produced by Schramm (1974).

\section{Background and references}

Previous work by this researcher has included the publication with Cokley of an argument concerning the usefulness of journalistic training to citizens in a 'new economy' characterised by heavy use of information and communications technology_concluding 'everybody could do well to become a journalist', (Duffield \& Cokley, 2006, p. 5). A study with Adams (2005) documented the structure and content of journalism and media courses at 55 Australian universities providing information on the interplay of skills-based learning and theory. The latter work drew on a categorisation by Debra Adams of blocks of units as 'professional practice', 'theoretical or contextual', and 'cognate disciplines', showing variations in the mix from one institution to another of rather standardised ingredients: journalism practice or theory, media or communication studies, or other elements, e.g. from humanities. Reference has been made to Stuart Adam (2001) on learning for journalism and life. A review was made of texts to provide students with basic theoretical references for their practice, in the general communication field, commencing with Schramm loc.cit.; applied theory and communication issues in McQuail (2005), and De Vito, including texts that might be recommended for the unit under discussion $(2003,2005)$.

For the task of investigating transfers from skills practice to knowledge of media, and yet broader understandings, this study drew on the literature of community of practice, as a research methodology suitable for collegiate work in professional fields. It has been developed from the ideas of Jean Lave (2008, 2009) and Etienne Wenger (1998, 2007) (Lave \& Wenger, 1991), on situated, or 'everyday' learning. An article by Mark Smith (2003, 2009) identifies the key aspect of this approach, as the notion of learning as a social process. Community of practice is a process of participation in a group working to a common purpose, with attendant development of social relations. Quoting Wenger (2007), he identifies the community of practice as people linked together both by joining in common activities, and by 'what they have learned through their mutual engagement in these activities' (Wenger, 1998). This is a concept of situation for individuals that makes them participants in generating meaning, their learning being more than 'learning by doing' or experiential 
learning (Wenger 2007). A community of practice then, has these characteristics: it is a group defined by its shared domain of interest. It functions as a community through joint work and discussions. It is a group of practitioners with a shared repertoire of resources such as tools or ways of addressing problems, i.e. shared practice (op.cit.). The premise offered in this article is that such a community of practice has been assembled from the professional cadre associated with planning and teaching the new university unit. This teaching group has put itself to work, to study, reflect upon, and learn about the educational process being set up in a new postgraduate university subject.

\section{Implementation of the proposal}

The formal proposal for inauguration of the new subject for postgraduate students emphasised the two central notions: a practitioner perspective and approach to knowledge; and a thinking out of a critical approach to media through practice. An offer by the university of two course-work Masters degrees (Master of Creative Industries-MCI, and Master of Journalism-MJ) in 2009 had seen significant enrolments and wide interest among prospective students. An invitation for proposals to widen the offering resulted in a prospectus for an elective unit in the degree structure, drawing on teaching practices in the Journalism discipline but available to all students in the two courses. It was proposed that practitioners could be engaged to teach introductory media practice, which many members of the public might be interested in learning-given the opportunities for applying skills through the internet, social media tools, mobile devices, digital cameras, and the like. This would be different to a 'practical' Journalism unit in that first, staff might be drawn from among persons with professional media credentials generally, not journalists only; the test being to have advanced skills to pass on. Second, there would be no focus on news; and third, various skills would be addressed, the skills training not to be intense. For example, it would not be a skills-building programme like a unit focused exclusively on news writing, driving to give students an enduring grip on writing passable copy over three-months. The unit would be characterised as introducing a set of life skills for a world dominated by the demands of communication media.

Documentation reflecting the ideas set out above was prepared by the researcher, as proposer for the unit, in early August 2010, for a university procedure involving: (a) Submission of an overview statement and draft Unit 
Outline (standardised summary document published on university databases, including an assessment guide-recognisable as a syllabus document), with costings, and approval of Portfolio Director (head of school); (b) evaluation by a peer group, the Faculty Board of Studies, recommending to the Faculty Academic Board; (c) approval by the Board and then Faculty Executive; (d) any revision and completion of the unit documents to accommodate the outcome of discussions at Faculty level.

Initial discussion with academic managers (viz postgraduate head, subject area coordinator - course coordinator), who would carry the proposal at the Faculty committees, required clarification on specific activities to be offered. Different interlocutors sought comparisons with existing classes. For instance, in discussions it was characterised briefly as an exercise in teaching online journalism though the proposed unit would be less specialised in terms of content and choice of media. At the management level the unit was identified as suitable also for the Continuing Professional Education (CPE) programme, i.e. fee-based offerings located outside of degree programmes. Because of that the name was changed to Fundamental Media Skills for the Workplace. It had been named, pro tem, Working Within Mass Media to indicate learning about media through a production-side approach. Approvals and adoption of the unit were completed in October 2010, and it was coded in the university's system, KKP410.

The Unit Outline emerged from the approvals process essentially intact. In it, the rationale for study was stated as follows: 'Knowledge of media and "media literacy" are increasingly important as life skills and vocational credentials, which also become important to 'non-media' professions; this unit adopts the principle that developing media production skills will both embellish individual competencies and materially assist with getting a clear understanding of media ...'

Similarly, aims were described as providing an overview of the way that media operate, placed in general social context; providing introductory practice in media production skills, working towards a showpiece product illustrating certain general characteristics of media; and assisting towards writing and publishing at a standard of professional competence. The notion of obtaining an understanding of principles through practice was evoked in the statement of intended learning outcomes: '1. Analyse media practice and production from a practitioner perspective in a range of settings in 
recognition of the increasing importance of media in society. 2. Demonstrate through foundational practice how a variety of media tools and forms such as audio, social media, or written features can be used to meet communication needs. 3. Demonstrate conceptual understanding and capacity to use a variety of communication tools in the production of a media artefact.'

\section{Consultations}

The general outlines for the unit had been presented to a meeting of staff in the journalism and media areas early in August 2010. An invitation to discuss the project was sent to 21 people, academics with professional background, mainly as journalists, or media practitioners working as sessional academics. Those invited could be expected to become involved in teaching the subject. As well as these consultative meetings, a 'community of practice' exercise was proposed for a little later, to investigate the possible patterns of learning that would occur. The latter process is the subject of the second half of this article. Three consultative meetings were held on September 24 and 28 with respectively four people (a managers' group), six, then three people in attendance.

At the first meeting of teachers the contributors proposed for content: blogging-writing briefs and posting them on a web log; getting pictures, editing, managing and publishing them; layout basics, towards a mock-up page for print, e.g. a newsletter. Discussion considered the limits of teaching, e.g. writing skills would be introduced but tutors might expect to have to subedit the material themselves before publication. The group determined how instruction could be offered within the standard frame of one hour's lecture time and two hours of tutorials or workshops weekly. Sessions involving invited guests from industry, would take place in lecture time, and in workshops such as an outdoor picture shoot, or editing session. The principal assessment item would be a media product developed from the skills training. For most people it would be a multi-media artefact, with exceptions for specialists in a particular branch of media, e.g. video-makers might work in that sole medium.

Five people at the second teachers' meeting proposed a section named 'community media' suitable for students wanting to use local media and make products like newsletters or media releases. An audio section was added, to involve hands-on work, on recording techniques and editing. The meeting considered assessment, laid out as two exercises: the main media product, and a report or essay on meanings and implications for community and society; 
noting that the latter should contain specific reference to the skills learning. The point was made that freeware should be preferred, for instance when choosing software to edit audio, consistent with the plan to enhance students' abilities in dealing with commonly available media tools. One schema submitted to the group as a stimulus for discussion: lecture sessions, to include industry participants, might promote the practitioner perspective on media issues; workshops would ensure a skills-based teaching approach, and assessment would consolidate and confirm learning through that approach.

\section{Transfer of learning}

A research phase was launched in the process of establishing the unit, to elaborate on the proposition that the teaching of it would expressly link practice and principles; seeking to provide some evidentiary basis, or at least an informed and compelling case for the seemingly reasonable assertion that this linkage must occur. As collegiate gatherings were being employed already, and as the researcher in this case had had experience with communities of practice notably in accreditation courses for higher degree supervisions, it was decided to adapt the COP approach to this inquiry. The outcomes of the COP were intended to validate the premise of the subject, that it would be generating knowledge through a transfer from skills to understanding, to be made explicit through review of the process by students in groups. The benefit to the course would accrue where the students' acquisition of knowledge from skills learning would be more explicit, less haphazard.

\section{Community of Practice - method of inquiry}

A pool of media educators was drawn on, including participants in the earlier working sessions, for a 'community of practice' exercise, which took place on October 26. The objective was to investigate and learn; an initial step towards judging what students in the new unit might experience at a psychological level as they undertook skills training and reviewed the experience. The exercise would share personal resources and professional understandings, in a task-orientated activity, to generate multiples of knowledge, ideas and analytical power within the group. The question for this group: By what mechanisms would the participants see students gaining a conceptual understanding of media through developing media skills?

Members of the group are practitioners, with engagement also in tertiary education. Again referring to Mark Smith, an assumption was made that 
these participants, generally known to one another or affiliated with the same university Faculty, have shared knowledge obtained through their mutual experience in teaching, related to their professional practice in journalism (Smith 1998). There were eight participants, listed by description, though unnamed, in Appendix 1. The session itself, which lasted for just under 90 minutes, will be referred to as the 'Community of Practice' or COP.

As outlined, this COP would try and identify a transfer from skills into knowledge, and make a credible description of how that transfer might occur. To that end, some guidelines were provided by the researcher, seeking to clarify the issue. Four readings were distributed, all book chapters which address the question of how skills relate to more abstracted knowledge, with some reference in each case to skilled work done in group situations.

Wilkins and Coleman (2005): 'The moral media ...' reports on research with a group of journalists on journalism ethics, finding that they attested to a process whereby they acquired their ethical guidelines overwhelmingly from colleagues, in a form of cooperative learning - though the author is able to argue that formal learning also was influential. This reading became a main preoccupation for the community of practice, because of the strong argument that learning was created and sustained by a practitioner group.

A second reading, from Hanrahan and Madsen (2005), 'Teaching, technology, textuality ...', was concerned with scholars in humanities adjusting their skills and knowledge to the demands of digital media - a learning project for practitioners, requiring reflection on the purposes of their work. The third case drew on Michel Dezuanni's (2009) chapter in Chi-Kim Cheung, Media Education in Asia, which considers training of high school students for engagement with media as a means for them to confront perceived problems with misleading publications, or mystification of media processes. It was posited in the COP that an opposite approach, as in the case of the proposed new subject for the university curriculum, of training first in media production skills, then reflection, would presuppose that media were not so problematic. It might also throw good light on ways that media operations function, and so inform thought and discussion on problems of society in regard to mass media.

The fourth extract was Peter Smith's (2010) 'Harnessing America's wasted talent ...', an argument for greater recognition by universities of knowledge developed and shared within groups of practitioners in the workplace, provided that, he says, such knowledge is developed and refined though conscious 
and systematic review. The proposition for the COP was that students in the proposed new unit might themselves be in the position of practitioners who could acquire knowledge by consciously revisiting and studying the implications of their work together.

In each case, the COP considered discourse about a body of knowledge (about ethics, knowledge in the humanities, media in society, abiding understanding drawn from work practices), and related skills (journalistic practice, using digital means in humanities publishing or research, skills for engaging with media, work practices). It considered how the knowledge and skills inter-acted, and how that might apply in the present case, of teaching media skills towards understanding of media and society.

To help clarify what might be meant by principles underlying practice in media, reference was made to the basic process model in a general communication theory: what messages were exchanged through which channels, with weakening factors in the equation (noise) or strengthening ones (feedback). This is also the main theoretical background proposed for study in the university unit, once again as an indicator, to students, of generalised understandings that might be drawn from the skills training.

This researcher chaired the COP and introduced the above guide as a pro forma for note-taking. The discussion had eight participants, who in the lead-up had received an outline on COP (together with a copy of the article by Mark Smith), references for the four readings (all full text on line), and a report on the preparatory consultations on the proposed new subject (pre-COP). Four of the participants had been involved in those earlier consultations. The identities of the eight participants, including the researcher, are not suppressed, but they are not used in reporting on the COP, with the intention of exploiting the collaborative character of a community of practice, and keeping the focus on the topic rather than persons.

\section{Outcome of COP discussion}

Referring to the readings as models for the discussion, firstly with the Wilkins and Coleman chapter; the participants concurred that in their experience of teaching or learning media ethics, foundational knowledge of moral philosophy would be referred to, but that the teaching focussed essentially on potential behaviour of media workers at a practical level, on the job, approached through case studies. That was seen as compatible with 
the notion of Wilkins, studying journalists, that they did not see themselves as learned in ethical discourse, but were aware of sharing values to do with maintaining rightful behaviour-fair reporting, privacy protections, balanced and informational styles of argument, and the like. The philosophy, it was suggested, was 'embedded' in the value system. In teaching, some of the key embedded concerns would be articulated and dwelt on, for example, the central practice, and value of journalism-verification.

One view proposed was that practices and skills shared by groups of practitioners amounted to a body of knowledge, learned and consciously maintained, which could ease the way to a good understanding of abstract values. For example journalists might build on their first impulses about whether to choose to use commons material, or fully copyrighted material, through referring to group knowledge and group practice; they might then go deeper, by considering the reasons for those practices, such as rights of ownership, theft or transgression against privacy.

Considering the Hanrahan and Madsen chapter as a model; discussion about knowledge in the case of production using digital media systems set up a dichotomy: On one hand was the observation that basics of writing and informing (e.g. regulated grammar or spelling, or conventions of storytelling), though not undermined by new formats, needed to be reinforced for the sake of maintaining clarity and therefore effective communication. On the other hand new formats, like innovative ways of storytelling, were considered, noting that communication devices associated with the internet had stretched the range of creative possibilities, and increased the expectations of learners. The two sides were seen as reconcilable, able to be managed simultaneously, in a complementary way by media practitioners. It would entail raised awareness of possibilities on the part of media workers. Again, learning through the job was to be involved, opening the way to a broader understanding upon reflection.

The COP's review of the extract from Dezuanni highlighted the proposition at the heart of the university unit being planned, that students interested in becoming media practitioners at any level might not only acquire skills for various media tasks, but expressly make linkages to obtain a more thorough understanding of media. They could profit from integrating different practical works, in different branches of media, into a single product, and so might also see the mass media phenomenon as more than the sum of its parts; and hopefully more easily grasp the place of this media in society. The observation was made that learners doing practical work, for example in 
journalism training, can be afraid of societal demands, such as legal complexities over intellectual property rights, and so skills ought never be promoted without also providing an understanding of pertinent links between media and society.

The 'new ecology of learning' evoked by Peter Smith emphasises that members of practitioner groups should conduct reviews of their workplace knowledge to refine it and have it recognised in higher education, as enduring and broadly applicable. This was noted in the COP, with the observation that reviewing of what is done in practice will be constructive at any level. It may begin with documenting simple responses to achieving outcomes with media production, or making comparative descriptions of products and achievements, going through to reasoning - over different views of what is being done, to an interpretative reconstruction of the way artefacts are being made and the general import of such changes.

\section{Conclusions of the Community of Practice}

The notion of reviewing and reflecting on the exercise of skills arises at each point in the discussion. A proposal made from the COP is to inject review and reflection into the teaching and learning program, and assessment for the new subject. That is seen as a way for teachers and learners to draw lessons from practice, about underlying assumptions and principles of human communication; and that process might be observed, to understand more about the tie-up, when learning goes on, between skills and knowledge. In an example discussed: It was suggested that students practising skills for corporate media, like media releases, reports or issues briefings, might study the positions being taken by clients who are not versed in media ways, compared to advice received from their own teachers about communicating with publics. Clients will frequently have information and messages of value they are unable to impart, for want of knowledge of the dynamics of public communication. In that way, when students are working on specific tasks and using the materials like briefing notes from clients for review and reflection, knowledge of this may translate into background understanding. Similarly, as example number two, writers preparing briefs for publication on websites might review their choice of forms of writing or expression, by trial and error, monitoring the response of users, and in the process they may make inferences about general characteristics of the communicative exchange among producers and users. 
This inferential process when identified by the students should be reported on in every instance. In assessment, it is suggested, a statement might be required of students linking practice done and conscious observation of what it shows about communication generally. This is considered within the intellectual capacity of postgraduate students from various disciplines who will be enrolled. It can be in a short essay on communication principles proposed as one of the two assessment items for the subject. It can also be part of an exegetical statement or framing document to accompany a main media product destined as the other assessment item. The premise offered in this article has been that theorised understandings of media in society, and predictive statements about the ways that human communication takes pace, may be unveiled in explicit and immediate forms through the practice of making media. That would indicate the presence of discovery, thought, and advanced learning. Though short of a detailed psychological study of learning processes, monitoring the review and reflection process could be expected to show something of how media practitioners, (like the journalists telling the scholar Wilkins about ethics), derive knowledge from their craft activities. With the projected students in this case being cast as the practitioners, and conducting their own reflection and review, a paradigm has been devised in tabular form, to represent a process that would be under way.

Table 1: Insertion of review and reflection into the unit
\begin{tabular}{|l|l|l|l|}
\hline $\begin{array}{l}\text { Intended progression in } \\
\text { this subject }\end{array}$ & $\begin{array}{l}\text { Process from skills learning to skills mastery to } \\
\text { reflection to generalised understanding }\end{array}$ \\
\hline What happens & $\begin{array}{l}\text { PRACTICE AND } \\
\text { INSTRUCTION }\end{array}$ & REVIEW & ASSESSMENT \\
\hline Achieving outcomes & What I did & $\begin{array}{l}\text { What I learned } \\
\text { from what I did }\end{array}$ & What I now know \\
\hline
\end{tabular}

\section{Outcomes and future development}

Confirmation of the Unit Outline, or syllabus for the subject, resulted in its publication with the course offering for the Summer Semester (21 November 2011 to 10 February 2012); see QUT home (www.qut.edu.au) > Courses $>$ Creative Industries $>$ Master of Journalism $>$ List A $>$ KKP410, ${ }^{2}$. The university does not have a standardised process for development of unit proposals, only the process for evaluating and approving them, explained under implementation of the proposal, above. The COP procedure was 
original among unit development schemes. It was done to clarify understandings, initially among the teaching group, of the rationale for this new postgraduate unit extending beyond the range of a single discipline. Further reviews are not mandated; new units are subject to the evaluation given to all, such as student learning experience surveys (LEX), Unit Health Checks or Course Experience Questionnaires. However the COP will reconvene to interrogate the coursework implemented, possible outcomes and lessons to be drawn. Members of the teaching/practitioner group work regularly with postgraduate students and consulted them informally on the development of the new unit. With that subject now being implemented student responses will be included in future COP discussions.

\section{General conclusions}

Two processes have been outlined in this report. The first is conventional work on constructing a skills-based teaching unit for graduate-level students, to empower them as users of commonly obtained media tools. The premise of this subject will be that adopting a media producer's perspective will produce fresh understandings for these learners, in media issues and the nature of communication generally. Demands of an 'information' society are given as a very suitable growing bed for this learning process. The second process outlined in this article is that being attempted by staff preparing to be engaged in the teaching, to infer from it, lessons in the nature of learning-specifically to investigate transfer of skills capabilities to wider and deeper knowledge. An exercise based on COP principles was conducted, and it transpired as a productive engine for processing information and ideas, operating to a task. It produced one main proposal in relation to the conduct of teaching, that ample time and some of the assessment effort in the new subject be devoted to supporting students, to themselves review and reflect on steps in their learning of skills and concepts. Progress in building and effecting the teaching of this unit of study is to be revisited from time to time in the context of community of practice.

With the report on the Community of Practice exercise, this article has presented a set of two situations where group-based learning (or discovery) and knowledge is discussed; the plan for students to learn principles through practice in workshops and other group situations; and the pedagogical thinking embarked on within the COP. 


\section{Notes}

1. Definitions: Course - a programme of studies usually extending over at least one year, made up of a set of units or subjects, leading towards the award of a university degree or other credential. Unit, paper or subject - a learning programme covering one particular aspect of the overall course, which unit normally will be taught over one semester. Conventionally there are four units or subjects in the course each semester. (Often universities call their units or subjects 'courses', with the overall degree programme then named something else, but that practice is not adopted in this paper).

2. Short URL for the Unit Outline, KKP410: http://tinyurl.com/424ls78 (22 April 2011)

\section{References}

Adam, G.S. (2001). The education of journalists, Journalism-Theory, practice and criticism, 2(3), pp. 315-339. London/Thousand Oaks, CA: Sage.

Adams, D., and Duffield, L. (2006). Profiles of journalism education: What students are being offered in Australia. Paper presented at the Journalism Education Association Annual Conference, Griffith University, 29 November-2 December 2005: Surfers Paradise, Queensland.

Cheung, C-K. (2009). Media education in Asia, Dordrecht: Springer. (Ebook).

DeVito, J.A. (2005). Essentials of human communication, (5th Edition). Boston, Mass.: Pearson/Allyn and Bacon.

Devito, J.A. (2003). Human communication: the basic course, (9th Edition), Boston: Pearson Education.

Duffield, L. and Cokley J. (Eds.) (2006). I Journalist. Sydney: Pearson Education.

Hanrahan M. and Madsen D.L. (Eds.) (2005), Teaching, Technology, Textuality: Approaches to new media, Basingstoke: Palgrave Macmillan. (Palgrave Connect eBooks).

Lave, J. (2009). The practice of learning. In Illeris, K. (Ed.), Contemporary theories of learning: Learning theorists - in their own words. London /NY: Routledge.

Lave, J. (2008). Everyday life and learning. In Murphy, P. and McCormick, R. (Eds.), Knowledge and practice : Representations and identities. Los Angeles /London: Sage.

Lave J. and Wenger E. (1991), Situated learning : Legitimate peripheral participation, Cambridge (UK)/ NY: CUP.

McQuail, D. (Ed.), (2005). Communication theory and research: An ECJ anthology. London: Thousand Oaks.

Schramm, W. (1974). The nature of communication between humans. In Schramm, W. and Roberts, D.F. (Ed.), The process and effects of mass communication (Rev. Edition). Urbana: University of Illinois Press.

Smith, M.K. (2003, 2009). Communities of practice. In the Encyclopedia of informal education. Retrieved on 17 November 2010, from www.infed.org/biblio/communities_of_practice.htm 
Smith, P. (2010). Harnessing America's wasted talent: A new ecology of learning. Hoboken: John Wiley and Sons. (Ebook).

Wenger, E. (2007). Communities of practice: A brief introduction. In Communities of Practice. Retrieved on 17 November 2010, from www.ewenger.com/theory/ Wenger, E . (1998), Communities of practice: Learning, meaning and identity, New York: CUP.

Wilkins, L., and Coleman, R. (2005). The moral media: How journalists reason about ethics, Mahwah NJ: LEA. (Ebook).

Dr Lee Duffield is a senior lecturer in journalism at the Queensland University of Technology, where he is engaged in postgraduate teaching and supervision, and assessment. His research interests include journalism curriculum development, particularly internationalisation, new media, foreign news emphasising media in Europe, and development news in the Pacific region. He is principal editor or author of three scholarly books and editor of the specialist publication EUAustralia Online. Lee Duffield was for more than 20 years an Australian Broadcasting Corporation journalist, including time as its European correspondent at Brussels. His article on a new post-graduate project at QUT was based on a paper given at the Journalism Education Association of Australia Annual Conference, University of Technology, Sydney, 24-26 November 2010.

\section{Appendix 1}

Participants in Community of Practice exercise 26.10.1.0

A - Academic (ASPRO), male, journalism practitioner (12 years)

B - Academic (Lecturer), male, journalism / public affairs practitioner (25 years)

C - Academic (Senior Lecturer), male, journalism / public affairs practitioner (28 years)

D - Academic (ASPRO), female, post-doctoral researcher, manager

E - Journalist, sessional academic, female, newspapers, online and corporate media, (6 years)

F - Journalist, sessional academic, female, radio and online journalism (6 years)

$\mathrm{G}$ - Photographer, male, online publishing, corporate manager, (15 years)

$\mathrm{H}$ - Doctoral student, sessional academic, female, $\mathrm{F} / \mathrm{T}$ academic (4 years), radio producer (3 years) 


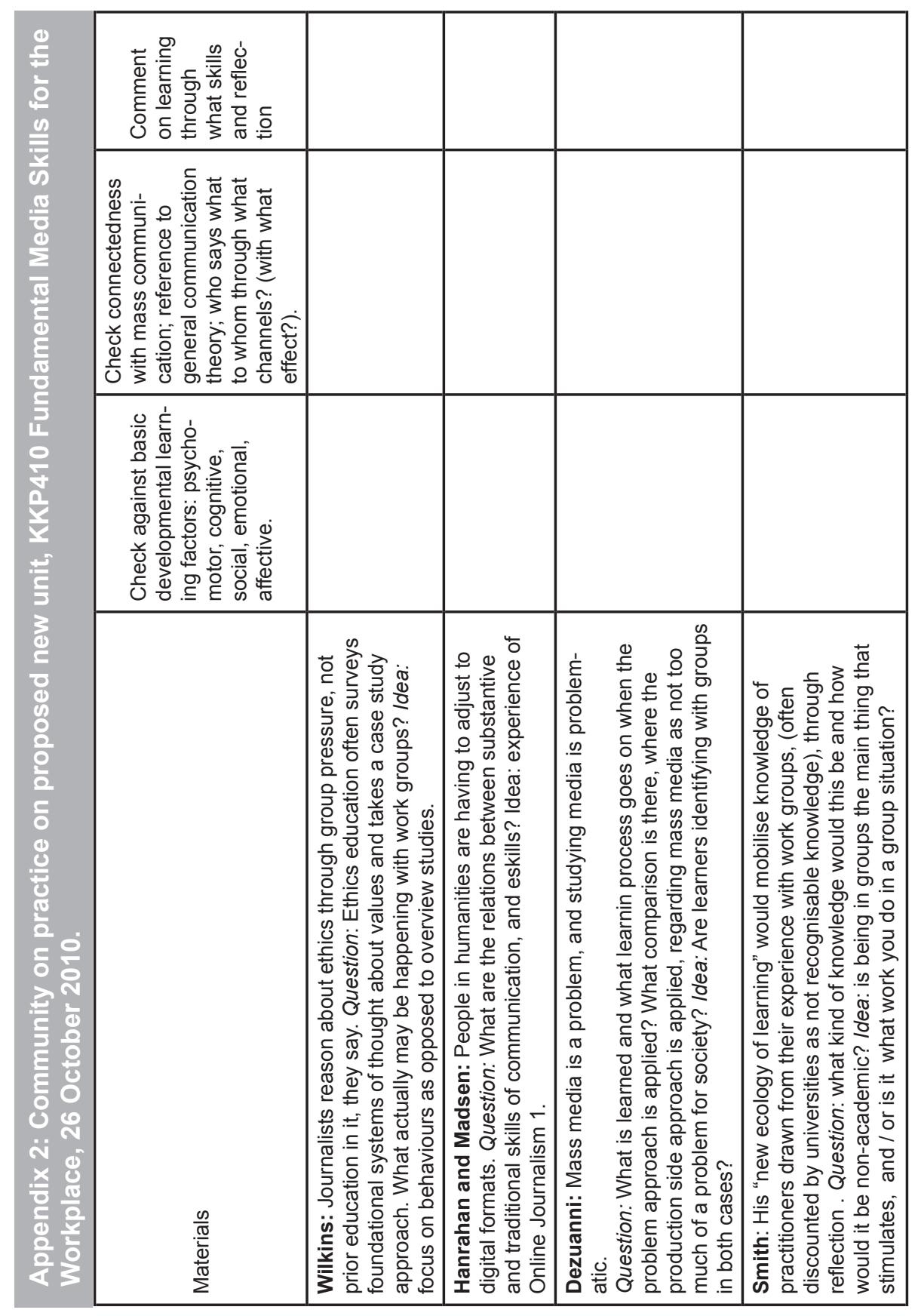

156 PACIFIC JOURNALISM REVIEW 17 (1) 2011 